\title{
JUVENTUDES E REDES SOCIAIS: interações e orientações educacionais
}

\author{
Lia Machado Fiuza Fialho' \\ Francisca Genifer Andrade de Sousa ${ }^{2}$
}

\section{RESUMO}

O advento das novas tecnologias tem alterado os modos de vida dos indivíduos na sociedade, em especial, dos usuários jovens de redes sociais. Questiona-se como se efetivam as interações juvenis com as redes sociais e quais orientações educacionais são mediadas por seus responsáveis, para o uso consciente dessa ferramenta. Realizou-se uma pesquisa qualitativa que envolveu 30 participantes - 15 jovens cearenses e 15 pais - com o objetivo de compreender a utilização das redes sociais pelos jovens e as mediações educacionais desenvolvidas pelos responsáveis para orientação ao uso crítico dessas ferramentas. A coleta de dados, realizada mediante questionários mistos, possibilitou constatar: tempo excessivo de utilização da internet pelos jovens, em maior proporção para acesso às redes sociais; Facebook, Whatsapp, Mensseger e Instagran, respectivamente, como aplicativos mais utilizados; relação de dependência com a internet e autoexposição; e ausência de orientação educacional veiculada pelos pais e pela escola aos jovens. As discussões desses resultados apontaram para relevância da formação de identidades juvenis desde a sociabilidade intermediada pelas tecnologias da informação e comunicação, o que gera a necessidade dos pais conhecerem e acompanharem as interações realizadas pelos seus filhos nas redes sociais para evitar situações de perigo e orientar o uso crítico e consciente com mediação educacional dialógica.

Palavras-chave: Redes sociais. Juventudes. Orientação educacional.

\section{YOUTH AND SOCIAL NETWORKS: interactions and educational orientations}

\section{ABSTRACT}

The advent of new technologies has changed people's way of life in society, especially those young users of social networks. It is questioned how effective youth's interactions with social networks are and which educational guidelines are mediated, by parents and tutors, for the conscious use of this tool. A qualitative

'Doutora em Educação (Universidade Federal do Ceará) e Pós-Doutora em Educação (Universidade Federal da Paraíba), Professora Adjunta da Universidade Estadual do Ceará (UECE) e do Programa de Pós-Graduação em Educação (PPGE/UECE), Fortaleza, Ceará. Email: lia_fialho@yahoo.com.br

2Mestranda do Programa de Pós-Graduação em Educação da Universidade Estadual do Ceará, Fortaleza, Ceará. Email: geniferandrade@yahoo.com.br 
research was carried out involving thirty participants - fifteen young people from Ceará and fifteen parents - in order to understand the use of social networks by young people and the educational mediations developed by those responsible for guidance on the critical use of such tools. The data collection, carried out through mixed questionnaires, made it possible to verify the excessive time young people spend on internet, in greater proportion with regard to access to social networks. Facebook, WhatsApp, Messenger and Instagram, are, respectively, the most commonly used applications; a dependent relationship with internet and selfexposure were also verified as well as some lack of educational guidance to young people from their parents and schools. The discussions of the results pointed to the relevance of the formation of juvenile identities from the sociability intermediated by information and communication technologies. That generates the need for the parents to know and follow the interactions carried out by their children in social networks to avoid dangerous situations and guide the critical and conscious use of social networks with educational dialogical mediation.

Keywords: First word. Second word. Third word.

\section{JUVENTUDES Y REDES SOCIALES: interacciones y orientaciones educativas}

\section{RESUMEN}

El advenimiento de las nuevas tecnologías ha cambiado el modo de vida de los individuos en la sociedad, en particular el de los usuarios jóvenes de redes sociales. Se cuestiona cómo se efectúan las interacciones juveniles con las redes sociales y qué orientaciones educativas son mediadas, por sus responsables, para el uso consciente de esa herramienta. Se realizó una investigación cualitativa que involucró a treinta participantes -quince jóvenes y quince padres- de la provincia de Ceará con el objetivo de comprender la utilización de las redes sociales por los jóvenes y las mediaciones educativas desarrolladas por los responsables de la orientación en cuanto al uso crítico de esas herramientas. La recolección de datos, realizada mediante cuestionarios mixtos, posibilitó constatar: el tiempo excesivo de utilización de la Internet por los jóvenes, en mayor proporción en lo que se refiere al acceso a las redes sociales; Facebook, WhatsApp, Messenger e Instagram, respectivamente, son las aplicaciones más utilizadas; relación de dependencia con la Internet y auto exposición; la ausencia de orientación educativa de los padres y de la escuela en los jóvenes. Las discusiones de estos resultados apuntaron a la relevancia de la formación de identidades juveniles desde la sociabilidad intermedia por las tecnologías de la información y comunicación, lo que genera la necesidad de que los padres conozcan y acompañen las interacciones realizadas por sus hijos en las redes sociales para evitar situaciones de peligro y orientar el uso crítico y consciente con mediación educativa dialógica.

Palabras clave: Redes sociales. Jóvenes. Orientación educativa.

\section{INTRODUÇÃO}

A vida na contemporaneidade vem sendo intensamente marcada pelas influências da tecnologia da informação e comunicação (OLIVEIRA, 
2012), temática central desta pesquisa. Se tratando de um fenômeno historicamente recente, é indiscutível a sua interferência nos modos de viver dos indivíduos, que têm sofrido uma diversidade de transformações no que tange aos modos de pensar, comportar-se e agir socialmente desde as interações virtuais.

Os insumos oportunizados pela nova forma de comunicação são denominados por muitos pesquisadores de cibercultura. No que se refere à relação entre os sujeitos e as novas tecnologias, Lévy (2009, p. 70) leciona que o conceito de cibercultura está intimamente associado à "forma sociocultural que emerge da relação simbiótica entre a sociedade, a cultura e as novas tecnologias de base microeletrônica que surgiram com a convergência das telecomunicações com a informática, na década de 70". No âmbito da cibercultura, compreendida também como um "universo de redes maiores ou menores, formadas por incontáveis nós, onde não habitam somente seres humanos, mas também computadores, softwares, máquinas, dados aplicativos, processadores, hipertextos [...]" (MIRANDA et al., 2015, p. 316), as redes sociais on-line é a área que mais concentra atenção (BITENCOURT; SOUSA, 2015).

Tendo começado a se desenvolver em termos materiais desde a década de 1980, com a ampliação do uso dos computadores pessoais (PCs), as redes sociais se expandiram substancialmente a partir dos anos 2000. Desde então, a comunicação por meio de conexões sem fio e o acesso a suportes, como tablets e celulares, ampliaram o uso das redes sociais a tal nível, que a conexão hoje, é contínua e adentra os espaços da esfera social "e nesses espaços, comunidades se formam e compartilham suas vidas, seus problemas, seus pensamentos" (SANTAELLA, 2010, p.3). Destaca-se a relevância de compreender tal fenômeno, posto que o incremento de uma vida em rede, ou seja, sempre conectada, se aprofundou a partir do momento em que a internet deixou de ser utilizada somente para fins acadêmicos ou profissionais e passou a ser aberta para todos, tornando-se a rede das redes (BITENCOURT; SOUSA, 2015). Nessa era digital, há o acesso a um local "não físico", mas que, no entanto, não é 
fictício, pois se constitui como promotor de uma comunicação informatizada que, ao possibilitar diversas conexões em um mesmo espaço de tempo, culmina na origem da cultura do ciberespaço. Desse modo, os indivíduos estão cada vez mais conectados, o que aponta para uma nova configuração da sociedade nos âmbitos da participação social, da atuação política e cultural (MIRANDA et al., 2015).

Considerando que a categoria 'tecnologia da informação e comunicação' é abrangente e extremamente complexa, optou-se por delimitar a investigação e pesquisar sobre as redes sociais, mais especificamente, acerca da maneira como os jovens as utilizam e as possíveis orientações educacionais que recebem para o manuseio dessa ferramenta. No panorama de usuários das tecnologias, são os jovens quem se destacam, principalmente pela sua agilidade no uso das novas ferramentas - controlam tanto os modos de comunicação quanto as máquinas com facilidade - além de dominar "vocábulos usuais do cotidiano que são utilizados com a intimidade de quem já nasceu em um mundo marcadamente tecnológico e digital" (SOUSA; LIMA; FONTE-BOA, 2015, p. 235).

Partindo da compreensão de que as juventudes do início do século XXI estão cada vez mais imersas no universo tecnológico, fazendo desse um ambiente primordial de relacionamentos via redes sociais e, portanto, considerando-as como ferramenta indispensável à vida moderna, torna-se relevante questionar como se efetiva a interação juvenil com as redes sociais e quais orientações educacionais os jovens recebem para o uso consciente dessa ferramenta. Ante essa problemática, realizou-se uma pesquisa, de abordagem qualitativa, que empreendeu uma investigação com 15 jovens cearenses e seus respectivos responsáveis, com o objetivo de compreender a utilização das redes sociais pelos jovens e as mediações educacionais desenvolvidas pelos responsáveis, para orientação ao uso crítico e consciente dessas ferramentas.

A apresentação desta pesquisa foi elaborada em 5 tópicos. O primeiro, em tela, denominado introdução, lançou lume a temática a ser 
discutida - juventudes e redes sociais-, sua delimitação - a mediação educativa fomentada pelos pais e responsáveis -, bem como, o problema e o objetivo a serem desvelados. O segundo, intitulado procedimentos metodológicos, explicita o caminho investigativo, considerando a aborgagem e o tipo de estudo adotados, os sujeitos participantes e os instrumentos de coleta de dados. Na sequência, inclui-se o tópico 'juventudes conectadas: uma compreensão inicial', que aborda o conceito de juventude utilizado na pesquisa, já que este é essencial para entender os presupostos teóricos que amparam a apresentação dos resultados e sua discussão elancados no tópico 'os jovens na interface com as redes sociais via internet'. Por fim, retoma-se a problemática e o objetivo geral para tecer as considerações finais, com a síntese dos principais achados e as reflexões emergentes destes.

\section{PROCEDIMENTOS METODOLÓGICOS}

O estudo apoiou-se em abordagem qualitativa, tendo em vista que $\mathrm{O}$ interesse em compreender a realidade dos sujeitos investigados se sobrepõe à análise quantitativa dos resultados (MINAYO, 2007). Instuiu-se realizar discussões aprofundadas acerca da relação do indivíduo com a sociedade, especificamente, da comunicação juvenil por meio das redes sociais e da mediação familiar no que concerne a orientações educacionais, salientando as subjetividades e os aspectos individuais que ficariam invisibilizados em estudos quantitativos e universalizantes.

De acordo com o Estatuto da Juventude (2013), são jovens, aqueles indivíduos entre a faixa etária de 15 a 29 anos. A partir da Política Nacional da Juventude, houve uma divisão entre esse grupo: "jovens na faixa de 15 a 17 anos, denominados jovens-adolescentes; jovens de 18 a 24 anos, como jovens-jovens; e jovens da faixa dos 25 aos 29, como jovens-adultos" (SILVA; SILVA, 2011, p. 664). Esse esclarecimento é necessário para anunciar que os sujeitos participantes dessa pesquisa são denominados jovens-adolescentes, haja vista que somente aqueles com idades entre 15 e 17 anos foram selecionados para participar do estudo. Essa faixa etária emergiu como 
critério de inclusão, pois se partiu da premissa de que os jovens dessa idade já possuíam maturidade suficiente para entender o objetivo da pesquisa e responder ao instrumento de coleta de dados, sendo, ainda, menores de idade e carentes de orientações educacionais.

Participaram da pesquisa 15 jovens e, ainda, 15 adultos que eram os responsáveis legais pelos adolescentes, todos residentes na região metropolitana de Fortaleza-CE. A escolha dos jovens participantes foi aleatória, considerando apenas o critério etário, logo, os colaboradores possuíam padrões socioeconômicos variados, estudavam em escolas distintas, tanto da rede pública como privada, e moravam em diversos bairros. Vinte jovens foram contatados pessoalmente, mas, após a abordagem individual com cada jovem, apresentado o objetivo da pesquisa e explicada a forma de participação dos jovens e seus responsáveis, apenas 15 participaram da pesquisa. Quatro recusaram-se a colaborar alegando que os seus responsáveis não iriam gostar da ideia de fazer parte da pesquisa. Um deles até aceitou participar, no entanto, ao contatar a sua responsável, ela alegou falta de tempo e disponibilidade para colaborar. Os 15 adultos, um para responder por cada jovem participante, foram pais ou mães, sendo envolvido o genitor que era considerado pelo filho o mais presente no âmbito educacional.

Em suma, após o contato individual com o jovem e sua autorização para prosseguir com a pesquisa, solicitava-se o contato do responsável que passava mais tempo próximo a ele para explicar mais uma vez o objetivo e a forma de colaboração. Na ocasião, tendo eles demonstrado interesse de participar do estudo, marcava-se um lugar a escolha dos pais para a coleta de dados, que variou entre o ambiente profissional, a residência e a escola do filho. Nesse momento, o jovem e seu responsável assinavam o termo de consentimento e se efetivava a coleta de dados.

A coleta de dados se desenvolveu por meio de um questionário para os jovens e outro para seus responsáveis, com questões mistas, respondidas individualmente após leitura e explicação das pesquisadoras. O questionário destinado aos jovens foi composto por oito indagações, sendo elas divididas 
entre perguntas fechadas e mistas, das quais cinco eram objetivas com respostas de múltipla escolha, nas quais era questionada a quantidade de tempo por dia em que o jovem utilizava a internet, a atividade que realizava ao utilizar a internet, quais redes sociais acessava, se os pais ou responsáveis tinham conhecimento sobre todos os sites e conteúdos acessados e se enxergava algum perigo no uso da Internet; e três eram mistas, nas quais era questionado se o jovem tem acesso à internet e onde se conectava; se os pais orientavam acerca do uso da internet e, em caso positivo, como se dava a orientação; se a escola orientava sobre o uso da internet e das redes sociais e, em caso positivo, era solicitado que o jovem especificasse como.

O questionário destinado aos responsáveis pelos jovens era composto por cinco perguntas que sondavam o conhecimento destes acerca da maneira como os jovens sob sua responsabilidade utilizavam as redes sociais. Dessas, três eram objetivas - por quanto tempo, em média, durante o dia, o jovem ficava acessado à internet; se possuíam conhecimento do conteúdo acessado pelo jovem; se o jovem já havia passado por alguma situação perigosa ao utilizar a internet - e duas eram mistas - se alguma orientação era fornecida acerca do uso da internet, caso positivo, descrever como; se tinha conhecimento dos perigos existentes no mundo virtual e, em caso positivo, quais poderiam citar.

\section{JUVENTUDES CONECTADAS: uma compreensão inicial}

A concepção de juventudes é intimamente relacionada ao contexto, às condições financeiras, econômicas e culturais em que o sujeito vive, visto que, conforme averiguado por Pais (2006), não há uma definição que possa abranger todo o campo semântico que o indivíduo jovem pode adquirir. $O$ que existe é um universo de percepções juvenis que são relacionadas a diferentes teorias. Por isso, ao invés de falar em jovem ou juventude, considera-se que há jovens e juventudes, por compreender tal categoria como temporal, dinâmica, plural e diversa que não se define apenas etariamente, mas desde o contexto social, cultural e econômico (FIALHO, 2015). A despeito dessa pluralidade, nos dias atuais, exemplo contundente 
de apropriação e ressignificação das juventudes se efetiva por meio da "interação constante com as novas tecnologias da comunicação e informação, especialmente da internet e seus mecanismos de sociabilidade" (VASCONSELOS, 2015, p. 111).

Perceber as juventudes na perspectiva plural é um desafio necessário para muitos pesquisadores e instituições que lidam diretamente com os jovens (OLIVEIRA; SANTOS, 2012). No meio acadêmico, por exemplo, são parcas as pesquisas que escutam os jovens e consideram suas percepções, ensejando visibilidade a suas experiências, seus interesses, modos de atuação, sua sociabilidade e suas manifestações (FIALHO; SOUSA, 2017). A maioria das produções discorre sobre as juventudes a partir da visão de adultos e de instituições ligadas à vida dos jovens, como a família, a escola, os centros de ressocialização, etc. (FIALHO, 2015).

Nesse contexto, o uso das novas tecnologias, em especial das redes sociais, "revela a peculiaridade da cognição e da socialização de um público que está transformando as relações sociais à sua volta, ao mesmo tempo em que percebe mudança na configuração de suas regras e valores, advindos da interação com as novas tecnologias da comunicação" (VASCONSELOS, 2015, p.112). À vista disso, é clara a interferência das tecnologias da comunicação na formação das juventudes atuais, dessa forma, pesquisar como acontece tal interação e participação dos jovens nesse espaço virtual torna-se importante.

Considerando a conjuntura social moderna, é indispensável se associar as juventudes ao contexto social em que se vivencia: o da tecnologia especialmente e, por conseguinte, da vida em rede, visto que, "para refletirmos sobre as juventudes contemporâneas, é imprescindível que as localizemos no âmbito da cibercultura e do ciberespaço, considerando, em especial, a internet e suas redes sociais" (MIRANDA, et al., 2015, p. 316).

A revolução tecnológica, além de ter desencadeado mudanças nos modos de comunicação e nas relações humanas, têm refletido, também, no comportamento das juventudes (CASTELLS, 2003). Nota-se um encantamento com as tecnologias, em especial às voltadas para a comunicação, pois são 
essas as que mais influenciam a vida dos jovens, tendo em vista a sua forte adesão entre esse público.

Para esses jovens, também conhecidos como "geração online", por terem nascido em uma época em que tudo está conectado, a internet se apresenta com capacidades ilimitadas de informação e comunicação, interferindo nos modos de vida das mais diversas gerações (OLIVEIRA; SANTOS, 2012, p. 3).

Sales (2011, p. 2) chama atenção para a diversidade de influências que as juventudes têm sofrido ao lidar com as novas tecnologias e centra foco no caráter social e cultural. Este autor diz que "falar de juventude e das novas tecnologias da informação e comunicação (NTIC) implica em percorrer um território sempre em fluxo." Além disso, o autor exemplifica a manifestação das tecnologias nos comportamentos juvenis, pontuando a ressignificação da linguagem ao se comunicar pela internet, ambiente em que pode ser evidenciado o uso de símbolos e palavras que ganham outros sentidos.

Obviamente, adolescentes e jovens descobrem o espaço virtual como campo fértil, com novas formas do social, que passam a fazer parte da vida cotidiana dos indivíduos. Eles desenvolveram novas formas de ver a si mesmos e o mundo, influenciando as práticas, as ideias e as maneiras de lidar com o mundo (FICHTNER, 2015, p.56).

Nesse rumo, "com as novas possibilidades de realizar a sociabilidade através dos artefatos tecnológicos, em especial a internet, observa-se uma modificação na maneira das pessoas interagirem, em especial os jovens" (OLIVEIRA; SANTOS, 2012, p.4). É vasto, todavia, o impacto das tecnologias na vida cotidiana dos jovens (FURLAN, et al., 2016), o que pode ser evidenciado ao analisar as formas como eles têm se apropriado de tais artefatos e o uso crescente da internet. Fato que demanda aprofundamento com investigações que interrelacionam a juventude e as redes sociais.

Mesmo considerando o aparato digital para decifrar as juventudes, o esforço voltado para mapear e caracterizar as relações por elas protagonizadas no ambiente virtual é complexo, pois ainda é escasso o suporte teórico para esclarecer determinadas peculiaridades desta relação 
(RECUERO, 2009; OLIVEIRA; SANTOS, 2012). "Um dos mecanismos da internet, ainda pouco estudado, no Brasil, pelo menos no nível da pós-graduação em educação, por exemplo, são as chamadas redes sociais digitais" (VASCONSELOS, 2015, p.105). Importa, pois, compreender como se efetivam as utilizações das redes sociais pelos jovens e quais mediações são desenvolvidas pelos pais ou responsáveis, para orientações relativas ao uso crítico e consciente dessa ferramenta.

Salienta-se, contudo, que esse estudo se propõe à natureza qualitativa, comparando os conhecimentos dos jovens e de seus reponsáveis, acerca do uso das redes sociais e as possíveis orientações educacionais para essa finalidade, logo, mesmo que existam bilhões de usuários ativos nas redes sociais, apenas uma pesquisa que considera as subjetividades juvenis, pode desvelar aspectos educacionais pertinentes com maior aprofundamento. As contribuições ensejadas não possuem intenção de generalizações, característica de pesquisas quantitativas, ao contrário, se torna significativa justamente por lançar luz a aspectos microsociais só visíveis em estudos qualitativos que permitem ouvir os jovens.

\section{Os jovens na interface com as redes sociais via internet}

A internet, prioritariamente as redes sociais, consiste em um campo que possibilita atuações diferenciadas por seus usuários. Para o público juvenil, por exemplo, as redes são mais do que um ambiente utilizado para se relacionar, pois também é espaço de aprendizado, de expressão e de troca de experiências (OLIVEIRA; SANTOS, 2012, p.10).

Dos 15 jovens que participaram da pesquisa, 6 estavam com 15 anos, 5 com 16 anos e 4 com 17 anos. Independente da idade, todos os jovens mantinham acesso diário à internet, sendo que 8 afirmaram manterem-se conectados, principalmente em casa, pelo computador, e os outros 7 disseram que ficam conectados prioritariamente pelo celular, logo, tanto em casa, como na escola e em outros ambientes eles acessavam à internet.

O tempo diário que a maioria dos jovens passava conectado à internet foi maior que 4 horas, já que apenas cinco afirmaram ficar de duas a 
quatro horas na internet. Os pais/responsáveis dos jovens confirmaram tais informações e demonstraram ciência da quantidade de tempo que eles dedicavam ao uso da internet. A julgar pelo panorama descrito vê-se que a internet não é, portanto, um ambiente visitado esporadicamente, ao contrário, consome parte considerável do dia desses jovens, motivo pelo qual, os jovens consideravam o uso da internet indispensável à vida. Vale ressaltar, ainda, que ligados a outras pessoas ou atividades virtuais, eles reconhecem que, secundarizam ou ignoram as pessoas que se encontram próximas.

Considerando as relações estabelecidas pelos meios tecnológicos, as redes sociais se tornam espaços de lazer, de encontros e de expressões juvenis em que é possível fazer descobertas, expor opiniões, conhecer saberes e pontos de vista diferenciados; mas precisam ser utilizadas com cautela e responsabilidade. Todavia, imerso nesse universo de possibilidades, não raramente, o jovem adentra experiências danosas às relações concretas, por intermédio do isolamento físico e da dependência, conforme enfatizam Oliveira e Santos (2012, p.13):

\begin{abstract}
Para os jovens, após um período de fascinação com a tecnologia, o envolvimento com ela aumenta, criando estruturas simbólicas de dependência e os sujeitos não mais se imaginam distantes do aparato tecnológico. [...] Com o celular eles escutam músicas, jogam, enviam torpedos, conversam, entram na internet, em salas de bate-papo e se abstraem do espaço institucionalizado da escola, a ponto de, muitas vezes, nem escutar o que os outros falam.
\end{abstract}

Estando, independente do espaço físico, sempre rodeados por apetrechos tecnológicos, "os jovens passam, então, a desenvolver relações e comportamentos que estão extremamente atravessados por uma subjetividade virtual, na qual eles têm a necessidade de estar sempre conectados" (MIRANDA et al., 2015, p. 307). Nesta pesquisa, constatamos que o uso contínuo e intenso das atualidades tecnológicas e redes sociais, pode acarretar vício e dependência por parte dos seus usuários, já que os jovens afirmam usar as redes sociais em casa, na escola e nos variados locais, para interagir virtualmente, distanciando-se do contexto a sua volta. 
Lévy (2009) denomina esse processo de substituição das relações reais pelas virtuais de "desterritorialização", haja vista que, ao relacionar-se prioritariamente através dos meios digitais, perde-se a consciência de espaço concreto. Desse modo, a presença física torna-se desnecessária e, banalizadas as relações virtuais, há sentimento de não pertencimento geográfico a um local específico. Por conseguinte, as concepções e vivências juvenis são afetadas pelo ciberespaço. "Essa é a lógica que reina entre os jovens, a da desmaterialização dos espaços, dos lugares e até das próprias relações que estabelecem com outros de sua faixa etária ou não" (OLIVEIRA et al., 2015, p. 115).

Em congruência, infere-se que os jovens da atualidade

[...] constituem um grupo geracional que tem como singularidade, entre outras características, a subversão dos sentidos relativos à convivência social, na medida em que as relações no campo virtual assumem maior relevância do que a comunicação face a face com seus pares (BASSALO; WELLER, 2015, p.238).

Esse pressuposto foi confirmado por Moraes (2015) em pesquisa desenvolvida com as juventudes fortalezenses. A autora averiguou que os próprios jovens reconhecem que, quando há exagero nas relações à distância, tende-se a haver prejuízo por parte dos envolvidos, conforme informa:

\footnotetext{
Se, por um lado, os jovens reconhecem que muitas vezes preferem estabelecer contato através das redes sociais digitais, seja pela comodidade ou pela facilidade de falar com alguém distante, por outro, afirmam que o exagero na utilização dessas redes sociais pode (des)socializar, visto que deixam de estar presentes e atuantes nas redes sociais sem a mediação da mídia, para estarem imerso no mundo digital" (MORAES, 2015, p.305).
}

Destaca-se, todavia, que "as tecnologias hoje não são definidas como determinantes, numa relação de causa e efeito na vida do sujeito. Distintas disso, elas possuem efeitos condicionantes que possibilitam formas específicas de existência, as quais não poderiam ser pensadas sem ela" (MIRANDA et al., 2015, p.295). Acessar excessivamente a internet, contudo, pode gerar sérios problemas que perpassam o âmbito social, pessoal e 
educativo, haja vista que tal conduta pode afastar o indivíduo do convívio direto com seus pares, gerar dependência e interferir no rendimento da aprendizagem do aluno. Em contrapartida, as redes sociais globais permitem que pessoas do mundo inteiro se comuniquem em tempo real em apenas um clique, viabilizando que jovens de diversos lugares mantenham vínculo mesmo que não haja contato físico. Acerca dessa relação, Dominski et al. (2013, p.28) julga que "tal comportamento faz com que impulsione o desenvolvimento da juventude no que se refere à comunicação, liderança, socialização, informação e aprender em escala internacional".

Para além dos problemas e benefícios emergentes com a comunicação mediada pelas redes sociais, esse canal permite a expressão do público juvenil, tornando-se, também, espaço de formação de identidades, considerando que "essas ferramentas servem de meios de comunicação e expressão de suas singularidades, contribuem para a formação de referenciais relacionados ao trato com os outros e consigo mesmo [...]" (MOREIRA, 2015, p.15). Vale destacar que, a partir do uso das redes sociais via internet, as juventudes adquirem novas formas de ser, de aprender e de interpretar o mundo que a cerca, associando a vida online com a sua sociabilidade, dado que se tornaram protagonistas na criação de novos modos de enxergar a si próprios e constituir identidades (OLIVEIRA, et al., 2015, p. 108).

Ao serem indagados a respeito das principais atividades desenvolvidas ao utilizarem a internet, 13 jovens responderam que conversavam com os colegas em redes sociais; 9 disseram que assistiam a filmes e séries; 4 passavam o tempo buscando fazer amizades (nas redes sociais); 4 jogavam e 9 faziam pesquisas. Pode-se verificar que o uso da internet é múltiplo e está diretamente relacionado ao interesse dos jovens ao navegar por este espaço, haja vista que, embora a comunicação apareça como a principal atividade exercida, a pesquisa e o lazer também se destacam. A interação no ciberespaço se mostrou variada (PAIS, 2006), porque há ambientes para conversar, pesquisar, jogar, ouvir música, ou seja, para entreter-se, informarse ou relacionar-se. Nesse cenário de possibilidades, "cada vez mais jovens 
usam essas mídias para realizar as mais diversas atividades: estudar, conhecer pessoas, namorar, manter sua teia de amizade, ter acesso à informação e ao conhecimento" (OLIVEIRA; SANTOS, 2012, p.12).

Em meio às múltiplas atividades desenvolvidas pelos jovens por intermédio da internet, a exercida com maior frequência foi a comunicação por meio das redes sociais, para conversar com os amigos ou fazer outras amizades, seguida por fazer pesquisa e assistir filmes e séries e, em menor proporção, jogar. As redes sociais, foco desta pesquisa, foi justamente a ferramenta mais preponderante, o que enfatiza a importância de compreensão acerca da utilização das redes sociais pelos jovens.

Dentre as redes sociais mais visitadas estão: o Facebook, seguido pelo Whatsapp, posteriormente, o Instagram e o Messenger. Outras redes como o Snapchat, Twitter, Tinder e Linkedln também são utilizadas pelos jovens, mas com menor frequência, como se observa no quadro 1, que mostra as redes sociais mais acessadas pelos jovens:

QUADRO 1: Redes Sociais mais acessadas pelos jovens

\begin{tabular}{|c|c|}
\hline Rede social & Número de contas \\
\hline Facebook & 14 \\
\hline WhatsApp & 12 \\
\hline Messenger & 08 \\
\hline Instagram & 08 \\
\hline Twitter & 06 \\
\hline Snapchat & 05 \\
\hline Tinder & 03 \\
\hline Linkedln & 03 \\
\hline
\end{tabular}

Fonte: Elaboração própria

Interessa esclarecer que não houve na pesquisa nenhum jovem que não fizesse parte de pelo menos duas das redes citadas no quadro 1. Os jovens possuíam conta e utilizavam, em média, quatro das redes sociais supramencionadas. Dois tinham conta e acessavam as oito redes. Dados que demonstram o uso intenso das redes sociais pelos jovens e a relevância desse espaço virtual na sociabilidade e constituição cultural das juventudes. Corroborando com essa discussão, Fichtner $(2015$, p.44) acrescenta que, "na 
participação ativa em sociedade de mídia, os adolescentes e os jovens aprendem uma técnica de cultura que é necessária para lidar com muitas situações na vida cotidiana e na profissão de hoje". Ao utilizar as redes sociais, o jovem se apropria da cultura, e nesta apropriação, conjuntamente, há desenvolvimento do âmbito social, o que contribui para o domínio de novos modos de expressão e comunicação. Nesse prisma, a vida conectada consiste também na expressão cultural do indivíduo jovem, pois "adolescentes e jovens aprendem as novas tecnologias como uma parte essencial de suas formas de vida cotidiana e também aprendem a integrar essas tecnologias conscientemente na estrutura dessas formas de viver como cultura" (FICHTNER, 2015, p. 455).

As redes sociais são espaços nos quais há, para os jovens, a noção de pertencimento, de intimidade e de reafirmação dos seus modos de vida e expressões. Inclusive, se pode, "provocativamente, pensar que na web o jovem traz para fora o que é de dentro, quer dizer, torna visível o que não é mostrável" (MOREIRA, 2015, p. 36). Por isso, eles consideram que nesse território, há mais liberdade para se exteriorizar do que nas relações concretas, o que implica considerá-lo como um local profícuo de construção e exposição de identidades.

Com tal característica, o uso das tecnologias da informação e comunicação:

[...] proporciona o surgimento de um indivíduo que também é capaz de passar por construções identitárias as mais variadas e abertas, ao longo de sua existência, quebrando paradigmas e negociando processos contínuos, em detrimento dos modelos mais fechados das gerações não expostas à cibercultura (OLIVEIRA, et al., 2015, p.102).

Considerar o impacto das redes sociais na vida dos jovens é reconhecer que o mundo virtual se tornou palco central das comunicações e encontros, que, em geral, acontecem principalmente a partir da formação de grupos. Tais espaços consistem em importantes expressões da vida dos jovens, que dividem seus medos e angústias, manifestam suas expressões 
religiosas, culturais e políticas. Portanto, a vida no ciberespaço também tem o caráter harmonizador entre os indivíduos, rompendo as fronteiras físicas.

Miranda et al. (2015, p. 296) ao versarem sobre as redes sociais, em especial acerca do Whatsapp, do Instagram e do Facebook, afirmam que tais mecanismos, ao serem utilizados pelos jovens:

Possibilitam uma comunicação em tempo real e favorecem a interação com pessoas de diferentes contextos, para conversas sobre assuntos de interesse comum, muitas vezes, mediante uma linguagem lúdica e informal, protegidos de possíveis constrangimentos frente à presença real do outro. Na rede, os jovens também têm a oportunidade de produzir conteúdos e publicar suas criações. Ferramentas como blogs e redes sociais digitais propiciam que os jovens registrem e compartilhem com seus pares reflexões, vivências e pensamentos de seu cotidiano, que refletem na construção de suas identidades.

Partindo de tal argumento, a noção de participação social adquire outro significado, tendo em vista que a interação, por vezes, acontece mais à distância do que presencialmente. A respeito desse novo modo de contato, Bauman (2004) afirma que, apesar de existirem aspectos positivos dos encontros virtuais, quando não há limites no uso das conexões eletrônicas, essa prática pode acarretar o desencontro real, o que resulta no afastamento das pessoas em seu sentido físico. Isso acontece quando os encontros virtuais são considerados suficientes e tendem a substituir os encontros reais.

Dentre 0 vasto cenário de experiências (positivas e negativas) viabilizadas a partir do uso das redes sociais entre o público jovem, Miranda et al. (2015, p.308-309) enumera as seguintes:

Possibilidade de dizer 0 que se pensa sem constrangimentos, arrependimento. Necessidade de compartilhar cada minuto da vida. [...] Contato com pessoas queridas distantes. Esvaziamento das relações face a face. Possibilidade de estar na rua com os colegas e na rede ao mesmo tempo. [...] Insegurança na rede.

Ante os benefícios e problemas que a interação por meio das redes sociais podem oferecer, é mister compreender como os jovens percebem essas questões e quais instruções educacionais são disseminadas no 
contexto familiar e escolar, para orientar o uso consciente e responsável desse espaço. Especialmente porque, notadamente, em meio a "[...] essa multiplicidade de orientações, as pessoas, dentre elas os jovens com seu encanto pelas tecnologias da informação e comunicação, mantêm certo distanciamento em relação ao sistema sociocultural" (VASCONCELOS, 2015, p.96), uma vez que as interações online, para eles, têm se apresentado, em muitos casos, mais importantes do que as relações presenciais.

Nota-se, portanto, que, se por um lado a internet tem sido instrumento de construção e reafirmação das identidades juvenis, nos seus espaços de interação, ela mesma oportuniza que tal identidade seja mutável (OLIVEIRA et al., 2015, p.105).

Considerando a diversidade de experiências propiciadas pelo ambiente virtual, que vai desde a interação com outros sujeitos, conhecidos ou não, às maneiras variadas de expressão, é preciso orientar os jovens a reconhecer os riscos da internet, pois "nenhuma geração antes incorporou tanto as mudanças tecnológicas, as formas de comunicação, a definição de humanidade, a certeza da mudança, o tamanho e a interdependência do mundo, da mesma maneira que esta geração [...]" (FICHTNER, 2015, p. 54). Se por um lado a internet é considerada palco de formação dinâmica de identidades e busca de individualidade, que muitas vezes não se concretizam na vida real; é nesse ambiente, também, longe dos olhos dos pais, que os jovens estão mais propícios a sofrer danos causados pelo uso incorreto desses mecanismos, já que o ciberespaço vem "dando condições, aos seus usuários, de assumirem papéis sociais novos que seguem normas desconhecidas" (OLIVEIRA, et al., 2015, p. 106).

$\mathrm{Na}$ contramão de uma boa orientação educacional despendida aos jovens, os achados do presente estudo, constataram a falta de comunicação entre os jovens e os seus responsáveis, no que concerne aos conteúdos que aqueles acessam na internet e às experiências que vivenciam nas redes sociais, o que se apresenta de modo negativo, visto que são muitos os perigos que rodeiam os jovens ao aventurar-se pela rede, sendo necessário o acompanhamento de pessoas capazes de lhes orientar. 
Os resultados da pesquisa demonstraram que, segundo os jovens, os pais não sabem que sites são acessados pelos seus filhos, tampouco o conteúdo veiculado. Apenas três jovens responderam que achavam que os pais sabiam por quais sites navegavam, enquanto 12 afirmam que certamente os pais não possuíam esse conhecimento. Em congruência, os pais confirmaram as respostas dos jovens, pois destes somente dois afirmam ter conhecimento dos conteúdos visitados pelos filhos; enquanto três diziam saber em parte, e a maioria, 10 dos responsáveis, admitiu não ter nenhum conhecimento.

De acordo com Monteiro e Osório (2008), a internet é considerada, pelos jovens, um dos únicos espaços onde eles podem ter a privacidade e se expressar sem a interferência dos pais. A juventude é frequentemente associada a um período marcado por descobertas, inclusive, a da própria identidade e, assim sendo, a ideia de se aventurar em um universo desconhecido parece ser atraente, já que

O mundo virtual aparece como um paraíso, um parque tecnológico no qual se brinca de artista, modelo, cantor, conquistador, viajante; brinca-se de criador de seres humanos. Os jovens se reconstroem no mundo tecnológico. Esse universo [...] é o mundo segundo o qual sua existência é uma obra transcendental do próprio homem, agora um ser supremo, criador e criatura, dotada de poderes divinos e com controle absoluto da sua e da existência dos outros (MOREIRA, 2015, p. 25).

E, longe do olhar e da fiscalização dos pais, na internet, mais precisamente nas redes sociais, os jovens ganham autonomia e liberdade para atuarem como acharem conveniente, muitas vezes, inclusive, sem refletir ou problematizar sua interação virtual. Com efeito, as redes sociais ofertam "superpoderes" aos seus usuários jovens, haja vista que nesse ambiente é possível ter distintas experiências ao mesmo tempo e empreender feitos impossíveis de serem postos em prática na vida concreta (PRIOSTE, 2013). Assim, "as identidades se multiplicam e tomam liberdades pouco conhecidas, gerando o poder de criar e recriar perfis múltiplos e 
mutáveis, questionadores do real e simbióticos do meio" (OLIVEIRA, et al., 2015, p.107).

De acordo com Fichtner (2001, p. 7), a teatralidade desenvolvida pelos jovens ao lidar com o mundo virtual é de suma valia para a formação da sua identidade, além de reforçar a participação social. Acerca deste pensamento, o autor afirma que "as máscaras construídas e usadas pelos jovens correspondem e representam determinados tipos de figuras, com os quais os jovens entram em papéis ficcionais e participam de encenações criativas". A comunicação, no entanto, pode assumir aspectos teatrais, resultando na criação de perfis falsos nas redes sociais que atuam sem compromisso com a ética e o respeito devido, o que preocupa os usuários.

Acerca dos perfis fictícios, eles foram considerados perigosos tanto pelos jovens, quanto pelos pais que participaram deste estudo. As narrativas de um jovem e de um pai, sequencialmente, permitem evidenciar tal afirmação: "Tem gente que cria conta fake na internet só para fazer o mal"; "Falo para ele tomar cuidado com pessoas estranhas, porque às vezes pode ser pessoa que não existe de verdade". A maior preocupação do uso das redes sociais se concentrou nos perfis falsos. Afinal, alguns jovens confirmaram ter se tornado vítima de enganos, principalmente, ao marcarem encontros escondidos de seus responsáveis.

Os pais, de um modo geral, demonstraram preocupação com a falta de maturidade e consciência dos jovens acerca dos perigos com os quais estes podem se deparar ao usar as redes sociais. Além dos perfis falsos, o aliciamento para o uso de drogas, envolvimento com atos infracionais, pedofilia e sequestro foram perigos reconhecidos e mencionados pelos pais, como se observa nas narrativas que seguem: "Ter contato com pessoas ruins, pedófilos, sequestradores"; "Manter amizades desconhecidas"; "Marcar encontros com gente que não conhecem, entrar no mundo das drogas, do crime"; "Se envolver com gente que não presta"; "Conversar com pessoas desconhecidas"; "Pedofilia, conteúdos impróprios, amizades desconhecidas"; "Amizades ruins". 
À medida que o uso das redes se torna cada vez mais frequênte, mais amizades virtuais são estabelecidas. Para Reis et al. (2012, p.6), os jovens, realmente, são os mais vulneráveis a tais riscos, pois "não têm uma opinião formada e, com isso, são fáceis de serem influenciados pelo que se deparam no mundo virtual." Em tais experimentos, corre-se o risco de vício de internet, cyberbullyng, agressão sexual e superexposição, visto que os jovens "vão se tornando mais independentes e passam a acessar as redes via celular e computador pessoal, entrando aos poucos na lógica do multiacesso e da mobilidade e publicando conteúdos próprios com maior frequência" (ROSADO; TOMÉ, 2015, p. 22).

Para a "superexposição", os jovens se apropriam da rede social como "uma espécie de diário, onde são relatadas as suas vivências e sentimentos. [...] percebe-se a tendência de publicar atitudes e pensamentos que anteriormente eram restritos ao íntimo de cada um" (MORAES, 2015, p. 303). Assim, há o espetáculo da exposição da vida pessoal quase que em tempo real (SIMMEL, 2006), o que, inclusive, é reconhecido pelos pais. Nesse viés,

Podemos afirmar que as redes sociais digitais, somadas aos velozes e portáteis instrumentos de comunicação (laptops, smartphones, tablets, influenciam no abarrotamento dos limites entre a vida pública e a esfera privada [...], uma vez que, estando sempre ao alcance dos jovens, facilitam o compartilhamento imediato de informações do dia a dia a todo instante (MORAES, 2015, p.302-303).

Considerando o desconhecimento dos pais acerca do conteúdo acessado virtualmente pelos seus filhos, era esperada uma orientação educacional precária, no que toca às experiências dos filhos no meio virtual, no entanto, neste estudo, ela não foi apenas precária, mas praticamente inexistente. Configurou-se uma contradição perceptível: os pais reconhecem a "superexposição" e, em parte, os perigos que a utilização das redes sociais pode acarretar, mas não se empenham em fomentar orientação educacional qualificada. De modo que dos 15 pais que responderam ao questionário, 9 afirmaram não orientar os filhos de maneira alguma, ao passo que, os outros 6 disseram aconselhar os jovens, sem constituir um diálogo, esporadicamente, com frases pontuais, tais como citam os jovens: "Eles 
dizem para eu não falar com estranhos"; "Falam que o uso da internet às vezes pode ser perigoso"; "Minha mãe diz para eu usar com consciência e não deixar as minhas senhas salvas"; "Falam para eu não ver pornografia e não falar com quem não conheço" ; "Para que eu preste atenção em tudo o que pesquiso"; "Dizendo que tem muita gente ruim na internet".

Nota-se que as abordagens dos pais são consideradas breves e superficiais até mesmo pelos jovens, o que pode ser mais preocupante pelo fato destes afirmarem, em maioria, não enxergar perigo algum com o uso da internet. Dos 15 jovens, 10 revelaram que não conseguem pontuar nenhum aspecto negativo da utilização das redes sociais, enquanto outros cinco conseguiram destacar alguns riscos: "Caso de drogas, namoro com pessoas desconhecidas mais velhas e más"; "Amizades com pessoas que a gente não conhece"; "Golpistas"; "Marcar encontros errados e conhecer gente que não é boa companhia"; "Raquers, vírus no computador."

"É importante que os jovens sejam capazes de avaliar criticamente os conteúdos, reconhecer perigos possíveis e proteger-se deles" (FICHTNER, 2015, p.44). Afinal, "são inúmeros os casos de adolescentes que são vítimas do mundo virtual, em que são aliciados por interagentes, sem perceberem o perigo desta persuasão, inicialmente sem contato presencial [...] (REIS, et al., 2012, p. 5). Contudo, o jovem somente saberá reconhecer os riscos do mundo virtual e evitá-los, se, primeiramente, contar com auxílio do âmbito familiar, pois "é responsabilidade dos pais educarem adequadamente os filhos em relação às redes sociais." (REIS, et al., 2012, p.5).

Oliveira et al. (2015, p.102) lecionam ser "esse novo sujeito imerso nas culturas digitais e capaz de se relacionar com vários atores ao mesmo tempo, por intermédio dos mecanismos tecnológicos hoje disponíveis nas sociedades", o que gera quase que uma autossuficiência em busca da informação. Essa autossuficiência também pode servir como instrumento que ocasiona retrocesso e alienação de si. A esse respeito, Moraes (2015, p.135) reflete que

A sociedade da ignorância é também aquela que tem toda informação disponível a um toque no mouse, ou na tela do ipad, mas que, ao mesmo tempo, não consegue processar esse caudal de 
dados e informações disponíveis [...] principalmente pela grande dificuldade de processar a informação e construir conhecimento, a partir de uma visão crítica da realidade.

Portanto, estando rodeados por diversos mecanismos tecnológicos e realizando variadas atividades ao mesmo tempo, como falar ao celular, responder e-mail, interagir no facebook e demais redes, o jovem tem deixado a desejar quando o assunto é se informar para se proteger em meio à tecnologia. Acerca disso, Monteiro $(2008$, p.7) nos diz que,

Do rol de riscos aos quais temos associado ao uso da internet, a questão da dependência tem merecido particular atenção [...] e a imagem que nos parece transmitir é a de que os jovens são máquinas de escrever mensagens, no tele móvel ou no teclado do computador, usurpadores da língua portuguesa, acéfalos devoradores de jogos inúteis, com distorcidas noções de amizades e simplesmente obcecados pelo que a internet tem de pior. [...] Tratase, sobretudo, de encontrar um equilíbrio saudável entre benefícios e malefícios.

Para Bitencourt e Sousa (2015, p. 328), é comum identificar as juventudes como irresponsáveis e imaturas, que comumente se envolvem em condutas perigosas, no entanto, "estereotipá-los em uma eterna condição de imaturidade, revela, entre outras situações, a omissão da responsabilidade do adulto na mediação dessas vivências", sendo dever tanto da escola, quanto da família orientar os jovens a manter uma relação saudável com os meios de comunicação, e, por isso,

Cabe à escola e ao adulto responsável problematizarem criticamente as experiências de seus adolescentes e jovens no ciberespaço. Não um nem outro, pois essa é uma responsabilidade compartilhada dentro dos limites de cada esfera. Está claro que navegar no ciberespaço é uma das práticas mais recorrentes para as juventudes e que tem influência direta em sua vida. Logo, assim como tantas outras instâncias que devem ser acompanhadas de perto pelos pais e professores, a internet também apresenta riscos que podem submeter os jovens a situações que demandem cuidado, proteção, monitoramento (BITENCOURT; SOUSA, 2015, p. 329).

No que remete ao papel da escola, tanto os jovens quanto os pais, declaram que as instituições de educação formal não têm orientado as juventudes a ter experiências positivas ao conectar-se às redes. Dos jovens, 
somente 4 dizem ter recebido alguma orientação e, ao serem questionados como foi tal direcionamento, eles transpareceram superficialidade na abordagem do assunto: "Uma professora disse para eu ter cuidado com perfis falsos e com homens mais velhos."; "Não usar a internet muito porque vicia."; "Viver no Facebook e Whatsapp atrapalha nos estudos"; "Não ver pornografia nos computadores da escola para não colocar vírus."

Identifica-se que a escola, assim como os pais, não tem discutido acerca do uso da internet na vida dos jovens e, muito menos, estimulado estes a repensarem condutas, ao aventurarem-se no meio virtual, já que os escassos pronunciamentos acima descritos revelam o quão a abordagem do assunto é limitada e pouco dialogada.

A internet, e principalmente as redes sociais, são ferramentas bastante utilizadas pelos jovens em suas relações no ciberespaço. Elas permitem a vivência de experiências relacionadas à vida social, o que tende a contribuir para a formação da identidade do indivíduo. Por isso, se faz necessário que pais e professores auxiliem os jovens a manter uma relação saudável nesse espaço fomentando orientações educacionais dialógicas e contextualizadas.

Moreira (2015) advoga que a aprendizagem e a sociabilidade das juventudes estão diretamente relacionadas à expansão das tecnologias da informação e comunicação, prioritariamente da internet. Ou seja, as redes sociais, embora muito associadas aos riscos que propiciam, também são espaços de aprendizado e construção para o jovem que não podem ser ignorados, já que,

Os usos das tecnologias de informação e comunicação reivindicam outros modos de ver os jovens e suas pequenas máquinas, não apenas os de submissão, de vício e fuga da realidade, normalmente empregados quando estamos indefesos diante de uma ameaça incompreensível. A questão do pertencimento, da conquista da autonomia e afastamento dos pais para se tornar adulto parece acompanhar o jovem em suas andanças nas redes (MOREIRA, 2015, p.35-36). 
Em congruência com esse pensamento, Corradini e Mizukam (2013) compreendem que as tecnologias da informação e comunicação, ainda que ofereçam riscos, se bem utilizadas, também podem subsidiar a formação do indivíduo, enquanto praticante da cidadania plena. Para isso, basta que tais tecnologias sejam usadas de modo a desenvolver o senso crítico dos jovens (MASSENSINI, 2011). Para o desenvolvimento de um uso responsável e consciente, que favoreça a autonomia e o empoderamento crítico juvenil, é necessário empreender esforços na orientação educacional dos jovens para o usufruto responsável das redes sociais, ensejando visibilidade às maneiras como os jovens se apropriam destas, ao invés de ignorá-las ou relegar tal interação ao segundo plano de importância.

\section{CONSIDERAÇÕES FINAIS}

Ao partir da hipótese de que as novas tecnologias acarretam mudanças nos modos de vida dos indivíduos na sociedade, em especial, dos usuários jovens que se comunicam e se relacionam frequentemente por intermédio das redes sociais, defende-se a tese de que é importante conhecer as interações virtuais desenvolvidas pelos jovens e orientá-los, no âmbito educacional, para o uso responsável e saudável das redes sociais. Desenvolveu-se, pois, uma pesquisa que questionou como se efetivam as interações juvenis com as redes sociais e quais orientações educacionais eram mediadas por seus responsáveis, para o uso consciente dessa ferramenta.

O objetivo, todavia, foi compreender a utilização das redes sociais pelos jovens e as mediações educacionais desenvolvidas pelos responsáveis para orientação ao uso crítico dessas ferramentas. Para desvelar este escopo, realizou-se uma pesquisa qualitativa que envolveu 30 participantes, sendo 15 jovens cearenses e um de seus respectivos responsáveis. A coleta de dados, realizada mediante questionários mistos, demonstrou que os jovens passam tempo excessivo utilizando a internet e que a maior parte desse período se destina ao uso das redes sociais, em especial, o Facebook, o Whatsapp, o Messenger e o Instagram. 
O tempo exagerado de uso das redes sociais enseja relevância para as novas formas de sociabilidade juvenis, interferindo na interação interpessoal e formação de identidades mediadas pelas tecnologias da informação e comunicação. O acesso virtual dos jovens demonstrou relação de dependência com a internet, autossuficiência, exposição a situações de perigo e distanciamento do convívio com as pessoas mais próximas.

Mesmo cientes de que o uso da internet pode oferecer benefícios acesso a informações em tempo real, apoio pedagógico, lazer, etc. - e malefícios - exposição às situações de perigo como pedofilia, perfis falsos, sequestros, drogas, atos infracionais, etc., os jovens e seus pais não nutrem diálogo sobre essa temática. A falta de conhecimento dos pais acerca do conteúdo acessado e das ferramentas utilizadas por seus filhos na internet, bem como, a ausência de orientação educacional veiculada pelos pais e pela escola aos jovens, apresentou-se como resultado preocupante nesta pesquisa.

Faz-se necessário reconhecer que a internet, especialmente no que concerne ao uso das redes sociais virtuais, é ferramenta agregada à rotina de vida dos jovens, que não pode ser invisibilizada em sua importância. Logo, orientar as juventudes sobre o uso crítico e consciente com mediação educacional dialógica torna-se emergencial, já que se registrou severa omissão educativa para conscientizar e auxiliar os jovens a tirar melhores proveitos das conexões virtuais disponíveis.

As juventudes são sujeitos históricos, dinâmicos e plurais que possuem especificidades. Resta claro, considerar que as diversidades presentes na atual conjuntura social são essenciais para intervir nas constituições identitárias de tais indivíduos, influenciando suas condutas, seus costumes, valores e suas percepções de mundo. Assim, considerar as redes sociais como veículos propulsores de formação social e cultural é inevitável, o que enseja atenção especial.

Mesmo se configurando uma pesquisa qualitativa, com número reduzido de participantes, que não suscita generalizações, a pesquisa em tela, lança luz à necessidade de fomentar orientações educativas 
significativas e contextualizadas para o manuseio saudável das redes sociais pelos jovens, na contramão da alienação e desterritorialização, proporcionando sua utilização consciente, crítica e cidadã.

No que tange às pesquisas que discutem sobre jovens e adolescentes, na perspectiva das redes sociais, muitos autores têm se dedicado a essa discussão, mas não foi localizada nenhuma pesquisa que investigue sobre os conhecimentos dos pais acerca do que os filhos acessam nas redes. Estudiosos como Lima et al. (2012) e Prioste (2013) se dedicaram a pesquisas com jovens no intuito de saber como tem sido firmada a relação desses sujeitos com as redes sociais, e, ao perceberem que os denominados nativos digitais estão expostos a perigos, sinalizam que os pais e a escola devem buscar mediar essa relação. Nesse sentido, salienta-se a originalidade deste artigo, visto que é pioneiro na tentativa de refletir acerca dos conhecimentos dos pais, corresponsáveis pela educação dos filhos, sobre o que sabem acerca da utilização que seus filhos fazem das redes sociais.

Bordignon e Bonamigo (2017) e Bonfim et al. (2016) asseveram que as redes sociais são espaços importantes para firmar a identidade juvenil, já que são um ambiente de interação e de socialização, se consolidando em canal de protagonismo social. No entanto, acrescentamos que a identidade cidadã somente é possível mediante interações harmoniosas, congruentes com os preceitos da vida coletiva, que devem ser acompanhadas e orientadas pelos educadores, sejam estes os pais ou profissionais da educação.

O estudo de Fernandes e Diniz (2016), realizado com adolescentes, por sua vez, averigua que os jovens fazem variados usos das redes, como interagir, postar fotos e acessar notícias, sendo mais consumidores do que produtores de conteúdo, e, por isso, demandando atenção por parte da família e dos educadores. Tais estudos constatam a relevância que as redes sociais possuem na vida dos jovens, mas não centram ênfase na maneira como os jovens estão sendo educados ou não para se apropriar, da melhor maneira, das ferramentas tecnológicas. Este estudo busca, para além de reforçar a importância das redes sociais na vida juvenil, ressaltar a 
necessidade eminente de educação atenta, especialmente por parte dos pais, que não apenas identifiquem interações, mas que acompanharem seus filhos e ensejem orientações constantes sobre os benefícios e perigos oriundos das interações nas redes sociais.

À vista desse panorama, esta pesquisa trata de um estudo pioneiro que lança reflexão acerca da distância entre como os jovens atuam nas redes sociais e o conhecimento de seus pais e da escola acerca dessa interação. Por conseguinte, a pesquisa em tela contribui para instigar ações educativas, haja vista que os conhecimentos aqui divulgados propiciam reflexões pertinentes no que remete ao modo com que as redes sociais têm interferido na vida dos jovens e, na contramão, como a família tem se portado fragilmente frente a essa relação.

\section{REFERÊNCIAS}

BASSALO, L. de M., B; WELLER, W. Jovem e mulher: um estudo sobre os posicionamentos de internautas feministas. In: SOUSA, C. A. M. (Org.). Juventudes e tecnologias sociabilidades e aprendizagens. Brasília: Liber Livro, 2015. p. 235-254.

BAUMAN, Z. Amor líquido: sobre a fragilidade dos laços humanos. Rio de Janeiro: Jorge Zahar Editor, 2004.

BITENCOURT, K, R de S; SOUSA, C, A, de M. Juventudes, escola e ciberespaço: um olhar sobre a experiência dos diários de classe virtuais no Facebook. In: SOUSA, C. A. M. (Org.). Juventudes e tecnologias sociabilidades e aprendizagens. Brasília: Liber Livro, 2015. p. 315-333.

BORDIGNON, C.; BONAMIGO, I. S. Os jovens e as redes sociais virtuais. Pesquisas e Práticas Psicossociais, v.12, n. 2, São João del Rei, 2017. Disponível em: <http://pepsic.bvsalud.org/pdf/ppp/v12n2/06.pdf>. Acesso em: 16. jul. 2018.

BRASIL. Estatuto da Juventude. Lei n 12.852. Brasília, 2013.

CASTELLS, M. A galáxia da Internet: reflexões sobre a internet, os negócios e a sociedade. Rio de Janeiro: Ed., 2003.

CORRADINI, S. N.; MIZUKAMI, M. G. N. Prática pedagógica e formação docente. Revista EXITUS. v. 3, n. 2, jul/dez 2013. Disponível em: 
<http://www.ufopa.edu.br/portaldeperiodicos/index.php/revistaexitus/article /view/152/152>. Acesso em: 11 Jan. 2018.

DOMINSKI, D. K.; BRITO, D. E. N.; SANTOS, I. N. dOs; RODRIGUES, J. A.; MOURA, E.; LOPES, R. M. F.; ESTEVES, C. S. Reflexões sobre a tecnologia e adolescentes: mitos e verdades. Revista de Psicologia. n. 20, 2013. Disponível em: <https://idonline.emnuvens.com.br/id/article/view/230/259>. Acesso em: 15 Jul. 2017.

FIALHO, L. M. F.; SOUSA, F. G. A. Política Pública de Juventudes: percepções dos bolsistas do Prouni. Jornal de Políticas Educacionais. v.11, n. 17. Nov de 2017. Disponível em: http://revistas.ufpr.br/jpe/article/view/53612/34014. Acesso em: 11 jan. 2018.

FIALHO, L. M. F. A vida de jovens infratores privados de liberdade. Fortaleza: Edições-UFC, 2015.

FICHTNER, B. A internet como prática cultural dos adolescentes: aspectos, problemas e resultados em uma pesquisa brasileira-alemã. In: Projeto de pesquisa intercultural sobre leitura e escrita de adolescentes brasileiros e alemães na internet (2000-2001). Juiz de Fora, MG: Universidade Federal de Juiz de Fora, 2001.

FICHTNER, B. Tecnologias da Informação e Comunicação (TIC) como prática cultural de adolescentes e jovens: uma perspectiva filosófica e epistemológica. In: SOUSA, C. A. M. (Org.). Juventudes e tecnologias sociabilidades e aprendizagens. Brasília: Liber Livro, 2015. p. 43-58.

FERNANDES, A. F.; DINIZ, L. A. Cibercultura e redes sociais: O acesso e a conexão definem as práticas das juventudes? Passagens, 2016. Disponível em: $\quad<h t t p: / / w w w . p e r i o d i c o s . u f c . b r / p a s s a g e n s / a r t i c l e / v i e w / 3595 / 3278>$. Acesso em: 16. jul. 2018.

FURLAN, F. M.; SILVA, M. A. da; BRAGA, R. N. F. Proeja e o significado socioeconômico da inserção do jovem no mercado de trabalho. Revista EXITUS. v. 6, n. 2. Jul/Dez de 2016 . Disponível em: <http://www.ufopa.edu.br/portaldeperiodicos/index.php/revistaexitus/article /view/30/30>. Acesso em: 11. Jan. 2018.

LÉVY, P. O que é o virtual? São Paulo: Ed. 34, 2009.

LIMA, N. L. de; SOUZA, E. P. de; REZENDE, A. O.; MESQUITA, A. C. R. Os adolescentes na rede: uma reflexão sobre as comunidades virtuais. Arquivos Brasileiros de Psicologia; Rio de Janeiro, v.64, n.3, 2012. Disponível em: <http://pepsic.bvsalud.org/pdf/arbp/v64n3/v64n3a02.pdf>. Acesso em: 16. jul. 2018. 
MASSENSINI, R. L. Inclusão digital: sob a ótica da cidadania plena. DataGramaZero - Revista de Ciência da Informação, v. 12 , n. 2, abr. 2011.

MINAYO, M. C. Pesquisa social: teoria, método e criatividade. 25. ed. Petrópolis: Vozes, 2007.

MIRANDA, L. L.; SOUZA FILHO, J. A. de; QUEIROZ, L. L.; VIANA, V. M. M.; COELHO, D. O. de C. Modos de subjetivação e redes sociais digitais: dialogando com jovens estudantes de escolas públicas de Fortaleza. In: SOUSA, C. A. M. (Org.). Juventudes e tecnologias sociabilidades e aprendizagens. Brasília: Liber Livro, 2015. p. 293-314.

MONTEIRO, A.; OSÓRIO, A. Mediação no uso da internet por crianças e jovens: contornos do problema. In: CONGRESSO PORTUGUÊS DE SOCIOLOGIA. Universidade Nova de Lisboa, 6, Lisboa, Anais... 2008. Disponível <http://www.fcsh.unl.pt/eukidsonline/docs/ComunicacaoAFM-AJO.pdf>. Acesso em: 20 jun. 2017.

MORAES, M. C. Conversando sobre ética, tecnologia e novas esperanças: é possível um futuro mais promissor para as novas gerações? In: SOUSA, C. A. M. (Org.). Juventudes e tecnologias sociabilidades e aprendizagens. Brasília: Liber Livro, 2015. p. 129-152.

MOREIRA, B. D. Os jovens e as tecnologias: entre a poética e o controle técnico. In: SOUSA, C. A. M. (Org.). Juventudes e tecnologias sociabilidades e aprendizagens. Brasília: Liber Livro, 2015. p. 21-42.

OLIVEIRA, J. A. de; SANTOS, C. de V. Juventudes e as novas tecnologias da informação e comunicação: tecendo encontros nas tramas das redes. Universidade Federal do Ceará - CE, 2012. Disponível em: <http://www.unicap.br/jubra/wp-content/uploads/2012/10/TRABALHO91.pdf> Acesso em: 10 jun. 2017.

OLIVEIRA, J. R.; DIAS, D. B.; LIMA, D. M. S.; SOUSA, C. A de M. O papel da internet na [re]construçãosócio-histórica da juventude: do jeans às redes sociais digitais. In: SOUSA, C. A. M. (Org.). Juventudes e tecnologias sociabilidades e aprendizagens. Brasília: Liber Livro, 2015. p. 101-128.

PAIS, J. M. Nos rastros da solidão: deambulações sociológicas. Porto: AMBAR, 2006.

PRIOSTE, C. D. O adolescente e a internet: laços e embaraços no mundo virtual. 2013, 113f. Tese (Doutorado em Educação) - Universidade de São Paulo, São Paulo, 2013.

RECUERO, R. Redes sociais da internet. Porto Alegre, RS: Sulina, 2009. 
REIS, M.; CUNHA, L.; MARQUES, A.; QUINTELAS, R. B.; BRITO, J. C.; RODRIGUES, L.; COSTA, M. O outro lado do Facebook. In: XI Congresso de Ciências da Comunicação na Região Norte. Palmas - TO, 2012. Disponível em: <http://www.intercom.org.br/papers/regionais/norte2012/expocom/EX29003 1-1.pdf>. Acesso em: $21 \mathrm{Jul} .2017$.

ROSADO, L. A. da S.; TOMÉ, V. M. N. As redes sociais na internet e suas apropriações por jovens brasileiros e portugueses em idade escolar: analisando resultados de duas pesquisas convergentes. Revista brasileira de Estudos pedagógicos. Brasília, v. 96, n. 242, p. 11-25, jan./abr. 2015. Disponível em: <http://www.scielo.br/pdf/rbeped/v96n242/2176-6681-rbeped-96-2420001 1.pdf>. Acesso em: 15 jul.2017.

SALES, C. de M. V. Juventudes, novas experimentações, conexões e interatividade. In: XV CONGRESSO BRASILEIRO DE SOCIOLOGIA, 2011, Curitiba. Anais... Campinas Curitiba, jan.2009.

SANTAELLA, L. Navegar no ciberespaço: o perfil cognitivo do leitor imersivo. 4. Ed. São Paulo: Paulus, 2010.

SILVA, R, S; SILVA, V, R da. Política Nacional de Juventude: trajetória e desafios. Caderno CRH, Salvador, v. 24, n. 63, p. 663-678, 2011. Disponível em: <http://www.scielo.br/pdf/ccrh/v24n63/13.pdf>. Acesso em: 03 mar. 2016.

SIMMEL, G. Questões fundamentais da Sociologia: indivíduo e sociedade. Rio de Janeiro: Zahar, 2006.

SOUZA, C, A, M de; LIMA, D, M, S; FONTE-BOA, F. Jovens universitários de licenciatura e a EaD em seus cursos presenciais. In: SOUSA, C. A. M. (Org.). Juventudes e tecnologias sociabilidades e aprendizagens. Brasília: Liber Livro, 2015. p. 155-172.

VASCONCELOS, I. S. O. A participação dos jovens em redes sociais virtuais: aspectos de uma experiência social. In: SOUSA, C. A. M. (Org.). Juventudes e tecnologias sociabilidades e aprendizagens. Brasília: Liber Livro, 2015. p. 81100.

Recebido em: 13 de fevereiro de 2018 Aprovado em: 30 de outubro de 2018 